(120.3 $\mathrm{mL} / \mathrm{kg} / \mathrm{min}$ (35.1) vs. $167.4 \mathrm{~mL} / \mathrm{kg} / \mathrm{min}$ (67.3); $\mathrm{p}$ value $<0.001)$ but remained stable by $10 \mathrm{~min}(189.2 \mathrm{~mL} / \mathrm{kg} / \mathrm{min}(26.2)$; $\mathrm{ns})$. The increase in LVO was significantly correlated to an increase in HR and left ventricle end diastolic diameter $(14.3 \mathrm{~mm}$ at $2 \mathrm{~min}$, $16.0 \mathrm{~mm}$ at $5 \mathrm{~min}$ and $16.6 \mathrm{~mm}$ at $10 \mathrm{~min} ; \mathrm{p}<0.001)$. We observed a bidirectional ductal flow in the first minutes, but large inspirations following a cry overruled the bidirectional ductal flow causing a large left to right shunting.

Conclusion At birth, the most significant hemodynamic change occurred in the first 5 minutes whereby an increase in preload and heart rate increased LVO. Inspirations had a major influence on ductal flow, causing large left to right shunting. Blood pressure at birth remained stable.

\section{EARLY POSTNATAL CHANGES IN SPLANCHNIC CIRCULATION IN HEALTHY TERM NEWBORNS}

doi:10.1136/archdischild-2012-302724.0106

${ }^{1} \mathrm{M}$ Zibolen, 'E Paulusova, ${ }^{2} \mathrm{~J}$ Zibolenova, 'L Kocvarova, ' $\mathrm{K}$ Matasova. ${ }^{1} \mathrm{Clinic}$ of Neonatology; ${ }^{2}$ Dept. of Public Health, Jessenius Medical Faculty Comenius University, Martin, Slovak Republic

Objective To characterize hemodynamic changes in celiac artery (CA) and superior mesenteric artery (SMA) in healthy term newborns during the first six hours after birth by means of Doppler ultrasonography.

Materials and methods The study included 30 healthy term newborns. The ultrasound examinations using Aloka $\alpha-10$ were performed at the age of 2.4 and 6 hours after birth. The statistical analysis of Doppler variables was performed using the non - parametric Friedman test with all pairwise multiple comparisons. Presented results are shown as median (interquartile range).

Results A reversed blood flow in SMA, documented by negative values of end diastolic velocity (EDV) [-10.90 cm.s-1 (-13.21-0.00)], changed to positive during the first six hours after birth $(7.08 \mathrm{~cm} . \mathrm{s}-1$ (6.29-13.48), $p<0.001)$. In CA, EDV increased in this period, but negative values were not recorded [11. 83 cm.s-1 (9.34-13.86) and 18.03 cm.s-1 (14.20-27.57) ].

Conclusion Dramatic changes occur in splanchnic circulation during the first six hours after birth. In superior mesenteric artery, the negative diastolic blood flow turns to positive as a part of circulatory transition in the presence of a ductal steal.

Acknowledgment This work was supported by project "Center of Excellence of Perinatology Research (CEPV II)", ITMS code: 26220120036, which is co-financed by EU sources.

\section{SURVIVAL OF VERY PRETERM CHILDREN BORN IN 2011: FIRST RESULTS OF THE EPIPAGE 2 COHORT STUDY}

doi:10.1136/archdischild-2012-302724.0107

1.2PY Ancel. 'INSERM Unit 953, Pierre-et-Marie-Curie University; ${ }^{2}$ INSERM Unit 953, Hopital TENON - APHP, Paris, France

\footnotetext{
Aims The number of neonates born preterm is increasing and children born at low gestational ages face a range of risks. We present the first results of the EPIPAGE 2 study, a national cohort of very and moderately preterm children in France.

Methods EPIPAGE 2 is a prospective population-based cohort study conducted in 25 regions of France in 2011 including extremely (22-26 weeks, 8-month recruitment), very (27-31 weeks, 6-month recruitment) and moderately preterm (32-34 weeks, 1-month recruitment) children. It aims to examine short and long term outcomes (survival, health and development) of these children and their determinants. Data on pregnancy, delivery, and neonatal events were extracted from the obstetric and neonatal records.
}

Results A total of 5565 births were included in the EPIPAGE 2 study: 1752 were born extremely preterm (898 (51\%) stillbirths and 854 (49\%) live births), 2728 very preterm (298 (11\%) stillbirths and 2430 (89\%) live births), and 1085 moderately preterm (28 (2.5\%) stillbirths and 1057 (97.5\%) live births). The survival rates for extremely preterm babies were $23 \%$ of all births and $48 \%$ of live births. The corresponding survival rates were respectively $83 \%$ and $93 \%$ at $27-31$ weeks and $96 \%$ and $99 \%$ at 32-34 weeks. In 1997 (EPIPAGE 1 study), the survival rates were $20 \%$ of all births and $46 \%$ of live births at $22-26$ weeks and $76 \%$ of all births and $88 \%$ of live births at 27-31 weeks.

Conclusion Survival has improved among very preterm children, but has not changed at extremely low gestational ages.

\section{ALTERED FRONTO-TEMPORAL NEUROANATOMY IN VERY PRETERM BORN ADULTS DURING COMPLETION OF A VERBAL FLUENCY TASK}

doi:10.1136/archdischild-2012-302724.0108

${ }^{1,2} \mathrm{~N}$ Garcia Casares, 'S Froudist Walsh, 'MP Allin, 'M Walshe, 'RM Murray, 'C Nosarti. 'Department of Psychosis Studies, Institute of Psychiatry, King's College London, London, UK; ' ${ }^{2}$ Centro de Investigaciones Medico-Sanitarias (CIMES), C/Marques de Beccaria 3, Malaga, Spain

Background and aims Several studies have described poorer cognitive performance in various aspects of language such as comprehension, naming, expressive language and verbal fluency in individuals who were born very preterm compared to controls. Neuroimaging investigations have also described structural and functional changes that could underlie such language deficits. In this pilot study we used functional MRI to explore whether alterations in the neuroanatomy of phonological verbal fluency persisted into adulthood following very preterm birth.

Methods Twenty-two young adults (26-28 years old, females=11, males=11) were examined. Eleven individuals were born very preterm (gestational age: $<33$ weeks) and 11 were full-term born controls. All participants underwent functional MRI using a 3T scanner while completing a phonological verbal fluency task. All data pre- and postprocessing was performed using FSL (www.fmrib.ox.ac.uk/fsl).

Results During successful verbal fluency trials, very pretermborn individuals showed significantly decreased blood-oxygenlevel-dependent signal compared to controls in several brain areas including the orbitofrontal/medial frontal cortex bilaterally $(x=8 \mathrm{~mm}, y=52 \mathrm{~mm}, z=-28 \mathrm{~mm})$ and the left fusiform/parahippocampal gyrus $(x=-34 \mathrm{~mm}, y=-30 \mathrm{~mm}, \mathrm{z}=-24 \mathrm{~mm}), \mathrm{p}<0.05$ family wise-error corrected (FWE). On-line performance did not significantly differ between the groups.

Conclusions Previous studies with functional MRI in younger samples have shown neuroanatomical alterations (increased and decreased activation) in fronto-temporal and fronto-striatal networks in very preterm born individuals when performing different cognitive tasks. Our results suggest that neuroanatomical alterations during language processing persist into adult life following very pre-term birth, and specifically involve fronto-temporal networks, with important implications for a wide range of high order cognitive functions.

\section{NEONATAL CEREBRAL OXYGENATION IS ASSOCIATED WITH NEURODEVELOPMENTAL OUTCOME OF PRETERM INFANTS AT 2 TO 3 YEARS OF AGE}

doi:10.1136/archdischild-2012-302724.0109

'EA Verhagen, 'KNJA Van Braeckel, 'CN van der Veere, ${ }^{2} \mathrm{H}$ Groen, ${ }^{1} \mathrm{PH}$ Dijk, ${ }^{1} \mathrm{CV}$ Hulzebos, 'AF Bos. 'Division of Neonatology, Beatrix Children's Hospital; ' 2 Department of Epidemiology, University of Groningen, University Medical Center Groningen, Groningen, The Netherlands 